\title{
Which Model Performs Better While Forecasting Stock Market Volatility? Answer for Dhaka Stock Exchange (DSE)
}

\author{
S. M. Abdullah'1, Mohammod Akbar Kabir¹, Kawsar Jahan², Salina Siddiqua ${ }^{3}$ \\ ${ }^{1}$ Department of Economics, University of Dhaka, Dhaka, Bangladesh \\ ${ }^{2}$ Department of Accounting \& Information Systems, University of Dhaka, Dhaka, Bangladesh \\ ${ }^{3}$ Department of Development Studies, University of Dhaka, Dhaka, Bangladesh \\ Email: abdullahsonnet@gmail.com, akbar_kabir03@yahoo.com,kjshumi@yahoo.com, selina.eco@gmail.com
}

How to cite this paper: Abdullah, S.M., Kabir, M.A., Jahan, K. and Siddiqua, S. (2018) Which Model Performs Better While Forecasting Stock Market Volatility? Answer for Dhaka Stock Exchange (DSE). Theoretical Economics Letters, 8, 3203-3222. https://doi.org/10.4236/tel.2018.814199

Received: September 25, 2018

Accepted: October 23, 2018

Published: October 26, 2018

Copyright $\odot 2018$ by authors and Scientific Research Publishing Inc. This work is licensed under the Creative Commons Attribution International License (CC BY 4.0).

http://creativecommons.org/licenses/by/4.0/

\section{Open Access}

\begin{abstract}
An efficient and well behaved capital market can be regarded as a prerequisite for the sustainable financial development for an economy. For making the stock market efficient and reducing uncertainty, volatility measure is necessary for the policy makers. The main objective of this paper is to examine relative ability of various models to forecast future volatility and to devise appropriate volatility model for capturing variability in stock returns of Dhaka Stock Exchange (DSE). By exploiting daily data spanning from $27^{\text {th }}$ November, 2001 to $31^{\text {st }}$ July, 2013, it was found that, from volatility persistency perspective $\operatorname{MA}(2)-\operatorname{GARCH}(2,1)$ is better due to both in sample and out of sample accuracy. In contrast, from capturing asymmetric effect perspective $\operatorname{MA}(2)-\operatorname{EGARCH}(1,3)$ is better. Thus, there was no clear winner and hence the decision should depend on the purpose of the concerned people.
\end{abstract}

\section{Keywords}

Stock Market, Volatility Forecasting, GARCH, EGARCH, Mean Equation

\section{Introduction}

Stock Market volatility is the variability in stock prices during a period which is perceived as a measure of risk by investors. It may affect business investments, financial market performance and economic performance directly [1] [2] [3]. Volatility of stock prices reflects uncertainty in the market. A rise in stock market volatility can often be interpreted as a rise in equity and thus a shift of funds to less risky assets; this move has been known to lead to a rise in the cost of 
funds to firms [1]. The understanding of stock market volatility could be useful in the determination of the cost of capital and in the evaluation of asset allocation decision. Policy makers may rely on estimates of market volatility as an indicator of the vulnerability of financial markets [4] [5]. Thus, the specification of appropriate volatility model for capturing variability in stock returns has a significant policy relevance to economic decision makers. Moreover, the ability to model and forecast volatility of asset returns is vital for investors in decision making about risk management and portfolio adjustments.

Like other developing countries in Bangladesh stock market is an emerging market but has been experiencing inefficiency from its inception. To make the market efficient and reduce uncertainty, volatility measure is necessary for the policy makers. The main objective of this paper is to examine relative ability of various models to forecast future volatility and to devise appropriate volatility model for capturing variability in stock returns of Dhaka Stock Exchange (DSE).

On this background already an enormous amount of effort has been made from the researchers to model the variance dynamics of stock market return and its different characteristics in Bangladesh [6]-[15]. Some of them have given effort to find only the volatility persistency property of the stock return, some tried to model only the risk return relationship while some other tried to forecast the volatility only. All the exercises tried to address the issue applying Generalized Autoregressive Conditional Heteroscedasticity (GARCH) family models developed by Bollerslev [16]. However, a few of papers have actually tried to figure out the best performing model for capturing the in-sample variance dynamics and out-of-sample variance forecasting. Also, identification of mean equation was either completely ignored or improperly identified and post estimation diagnostic checking was also improper resulting in some findings which could remain as questionable. The current study first aimed to develop appropriate mean equation and model the variance dynamics in stock return using number of linear and non-linear GARCH family models. Secondly it made an effort to select an appropriate in sample variance model while capturing its different feature and also tried to find out the best one while out of sample variance forecasting is the purpose.

The rest of the article is organized as follows: Section 2 provides an overview of existing literature, Section 3 discusses about data, variable construction and model specification and Section 4 contains the estimation results and findings. Finally, Section 5 concludes.

\section{Literature Review}

Several researchers have examined the volatility of stock returns of Dhaka Stock Exchange (DSE). They considered different models for different time period and sample size and found contradictory results in some cases. Rayhan et al. [8] considered the data set of monthly DSE General Index (DSE-GEN) from January, 1987 to March, 2010 and result revealed that DSE monthly returns do not follow 
random walk. The study also revealed that monthly DSE returns follow Generalized Autoregressive conditional Heteroskedasticity (GARCH) properties. Nevertheless Uddin et al. [15] while testing the efficient market hypothesis in pricing securities and the relationship between stock returns and conditional volatility argued that the stocks in DSE follow a random walk. Therefore the market might meet the criterion of weak form efficiency. The results of GARCH (p, q) model indicate the tendency for returns to exhibit volatility clustering.

Earlier Huq et al. [11] considered daily stock exchange data (general index) from December 06, 2010 to March 12, 2013, for building time series modeling and forecast. They used both symmetric and asymmetric models and found that the model $\operatorname{ARMA}(1,1)$ with $\operatorname{GARCH}(1,1)$ and $\operatorname{GARCH}(2,1)$ are more appropriate model for the general index of Dhaka Stock Exchange (DSE) for the said study period. Aziz \& Uddin [13] also estimated volatility in the DSE general index returns by $\operatorname{GARCH}(1,1)$ models and found that the volatility is present in the stock market in Bangladesh which is decreasing over time. The appropriateness of $\operatorname{GARCH}(1,1)$ model has also been endorsed by Miah \& Rahman [14] who have employed Dhaka Stock Exchange (DSE) returns of four selected companies, namely BEICL, BPL, PBL and ABBL for the period January 2000 to November 2014. On a different note Basher et al. [7] empirically investigated the time-varying risk return relationship within a GARCH-type framework and the impact of institutional factors like circuit breaker on volatility for the stock market of Bangladesh. The results showed a significant relationship between conditional volatility and stock returns, but the risk-return parameter is found to be sensitive to choice of samples and frequencies of data. While lock-in did not have any overall impact on stock volatility, the imposition of a circuit breaker has contributed significantly to the volatility of realized returns.

With a view to capture the asymmetric effect during 90s Chowdhury [6] analyzed the time series behaviour of Dhaka Stock Exchange Composite Index returns using the EGARCH-M model for the sample period December 1, 1988 to May 31, 1994, totaling 1519 observations. He concluded that there is asymmetry in the volatility of stock index return and unlike in the developed stock markets, positive return shocks in Dhaka stock market lead to higher increases in conditional volatility. In-sample and out-of-sample forecasting accuracy has been considered by Rahman et al. [9] with the GARCH, EGARCH and APARCH models in case of Dhaka Stock Exchange (DSE) from the period January 02, 1999 to December 29, 2005. Later on Alam et al. [12] investigated the use of ARCH class model for forecasting volatility of the DSE20 and DSE general indices by using the daily data from December 1, 2001 to August 14, 2008 and from August 18, 2008 to September 10, 2011 as in sample and out of sample sets respectively. Based on in sample statistical performance, both the ARCH and PARCH models are considered as the best performing model jointly for DSE20 index returns, whereas for DSE general index returns series, ARCH model outperforms other models. According to the out of sample statistical performance, 
all models except GARCH and TARCH models are regarded as the best model jointly for DSE20 index returns series, while for DSE general index returns series, no model is nominated as the best model individually. Islam et al. [10] examined the relative ability of various linear and nonlinear models to forecast daily stock indexes of future volatility of Dhaka Stock Exchange (DSE) index DSE-20 and found that linear moving average model outperforms other linear and nonlinear models.

It is widely accepted that while modeling the variance the mean equation is of vital importance. As failure of appropriate model detection for mean might result in less efficiency of parameters used in variance model due to potential presence of autocorrelation. This issue has largely been ignored in the stock market volatility literature in Bangladesh. Thus, the current study would at first optimize the mean equation while quest for modeling the variance dynamics in stock return. The main contribution here would be to set up appropriate volatility model for efficiently capturing variance dynamics in stock returns of Dhaka Stock Exchange (DSE).

\section{Methodological Framework}

\subsection{Data and Variable Construction}

This paper has exploited the daily data on general stock price index of DSE spanning from $27^{\text {th }}$ November, 2001 to $31^{\text {st }}$ July, $2013^{1}$. Although there are regular fluctuations in the movement of stock price index, generally they do contain the unit root property and hence can be characterized as nonstationary in nature. Thus, we have used logarithmic transformation to convert the data into stock market return which would have greater possibility to be stationary and appropriate for analysis. We have used the following formula to measure the return:

$$
r_{t}=\ln (P)-\ln \left(P_{t-1}\right)
$$

Here, $r_{t}$ stands for stock market return at day $t, P_{t}$ and $P_{t-1}$ stands for general stock price index at day $t$ and day before $t$. EViews 9 has been used as the statistical software for performing quantitative exercise.

\subsection{Model Specification}

The perfect modeling of conditional mean can be considered as a prerequisite of correct model specification of conditional variance of stock market return. Along with independent variables researchers of volatility modeling usually augment the conditional mean model either with Autoregressive (AR) or with Moving Average (MA) or even with a mixture of these two (Autoregressive Moving Average, ARMA) process [17]. In our case to serve the purpose we have used both AR $(p)$ and MA $(q)$ specification with sufficient lags in the following way:

${ }^{1}$ The data has been limited to this period because of the change in Index definition during 2013. 


$$
\begin{aligned}
& r_{t}=\mu+\sum_{i=1}^{p} \theta_{i} r_{t-i}+\varepsilon_{t} \\
& r_{t}=\mu+\sum_{i=1}^{q} \phi_{i} \varepsilon_{t-i}+\varepsilon_{t}
\end{aligned}
$$

where, $\mu$ is the constant term, $\theta_{1}, \theta_{2}, \cdots, \theta_{p}$ and $\phi_{1}, \phi_{2}, \cdots, \phi_{q}$ are the lagged coefficients and $\varepsilon_{t}$ is a white noise process. For modeling the volatility in stock market return using the above two different types of mean equation, the variance equation is specified following family of GARCH models namely, Standard GARCH, APARCH, EGARCH and IGRACH models. GARCH models developed by Bollerslev [16] are superior to their earlier versions called ARCH developed by Engle [18] as they ensure improvement in efficiency due to required estimation of lower number of parameters. However, consider the following general specification of the variance model:

$$
\varepsilon_{t}=\sqrt{h_{t}} v_{t}
$$

Here, $v_{t} \sim \operatorname{iid}(0,1)$, and specification of $h_{t}$ will determine different varieties of GARCH family models while each of which will serve specific purpose. For analyzing the different feature of stock market return by modeling its volatility we have estimated the following models:

$$
\begin{gathered}
\operatorname{GARCH}(p, q): h_{t}=\eta+\sum_{i=1}^{q} \alpha_{i} \varepsilon_{t-i}^{2}+\sum_{i=1}^{p} \beta_{j} h_{t-j} \\
\operatorname{APARCH}(p, q): h_{t}=\eta+\sum_{i=1}^{q} \alpha_{i}\left(\left|\varepsilon_{t-i}\right|-\gamma_{i} \varepsilon_{t-i}\right)^{\delta}+\sum_{j=1}^{p} \beta_{j}\left(h_{t-j}\right)^{\delta} \\
\operatorname{EGARCH}(p, q): \ln h_{t}=\eta+\sum_{i=1}^{q}\left(\alpha_{i} \frac{\varepsilon_{t-i}}{\sqrt{h_{t-i}}}+\lambda_{i}\left|\frac{\varepsilon_{t-i}}{\sqrt{h_{t-i}}}\right|\right)+\sum_{j=1}^{p} \beta_{j} \ln \left(h_{t-j}\right) \\
\operatorname{IGARCH}(p, q): h_{t}=\sum_{i=1}^{q} \alpha_{i} \varepsilon_{t-i}^{2}+\sum_{j=1}^{p} \beta_{j} h_{t-j}, \quad \text { where, } \sum_{i=1}^{q} \alpha_{i}+\sum_{j=1}^{p} \beta_{j}=1
\end{gathered}
$$

Here, in $\operatorname{GARCH}(p, q)$ model, $p$ and $q$ denotes the lag order of GARCH and ARCH terms respectively. In order to have well behaved variance restrictions on the parameters needed to be imposed, for instance, $\eta>0, \alpha_{i} \geq 0$ and $\beta_{j} \geq 0$. The volatility persistence will be measured by summing up the ARCH and GARCH coefficients $\left(\sum_{i=1}^{q} \alpha_{i}+\sum_{i=1}^{p} \beta_{j}\right)$ which is expected to be less than unity to have a stationary residual and nonnegative variance.

APARCH model developed by Ding, Granger \& Engel [19] is used to capture the nonlinear variance equation. Similarly as before $p$ and $q$ denotes the lag order of GARCH and ARCH terms with $\beta_{j}$ and $\alpha_{i}$ as their coefficients respectively. The parameter $\delta$ denotes the power parameter which is expected to be strictly positive. In particular the parameter of interest in such models is $\gamma_{i}$; the significance of which ensures the presence of leverage effect. The $\gamma$ parameter addresses the leverage effect of order up to $k$ where, $\left|\gamma_{i}\right| \leq 1 \forall i=1,2, \cdots k$ and $\gamma_{i}=0 \forall i>k$ and $k \leq q$.

Another volatility model that captures the asymmetric effect is EGARCH de- 
veloped by Nelson [20]. In the above EGARCH specification $\beta_{j}$ is the parameter measuring persistence in volatility, $\alpha_{i}$ is the parameter measuring leverage effect and hence named as "asymmetry parameter", finally $\lambda_{i}$ is the parameter measuring magnitude of the shocks and thus named as "size parameter". Since EGARCH expressed conditional variance as an exponential function unlike the earlier models it is not subject to nonnegativity restrictions.

Engle \& Bollerslev [16] have pioneered the IGARCH model for modeling the variance which is nonstationary in nature. Thus, IGARCH can be characterized as non stationary $\operatorname{GARCH}$ model. In the above $\operatorname{IGARCH}(p, q)$ process the sum of ARCH and GARCH coefficients would be equal to unity and thus individually they would contain a value less than unit.

To choose among the conditional heteroscedasticity models we have compared their out of sample volatility forecasting performance. In particular different models with several specifications have been compared in terms of Root Mean Square Error (RMSE), Mean Absolute Error (MAE), Mean Absolute Percent Error (MAPE) and Theil Inequality (TI) for identifying the most appropriate one with the current data.

\section{Estimation Results and Findings}

\subsection{In Sample Estimation Results}

As discussed in Section 3 it is imperative to identify the conditional mean model appropriately for modeling the volatility in concerned variable. Therefore, selection of estimation method of conditional mean model for stock return series is of vital importance. Figure A1 (Appendix) presents the time series graph of DSE General Index and their corresponding stock return series and Table A1 (Appendix) contains the summary statistics of the DSE General Index. It is quite evident from the figure that behavior of DSE General Index would be non stationary as the possibility of mean reversion would be very low. In contrast, since the mean reversion would possibly be quite frequent in stock return series it might exhibit the stationary behavior. To shed light on the perception we have from graphical analysis of this two series, statistical tests have been performed. Table A2 (Appendix) contains the test results for the unit root property of the stock return. We have used two different tests to diagnose the property; Augmented Dickey Fuller (ADF) [21] and Kwiatkowski-Philips-Schmidt-Shin (KPSS) [22]. The former one test the null of non-stationarity of the series while the later considers the null as the stationary one. Both the tests have been performed with two different specifications; one with drift and the other with drift and trend. As the results show we can reject the null of non-stationarity of stock return in both test specifications under $\mathrm{ADF}$ at 1 percent level. On the other hand while performing KPSS test the null of stationarity of the variable was not possible to reject as the calculated value of test statistic was found to be lower than its corresponding 1 per cent critical value (Appendix: Table A2). Thus it can be argued with evidence that the stock return series is stationary and we can 
use OLS directly as estimation method for the conditional mean models.

The conditional mean model for stock return has been developed with two specifications one with AR terms and the other with MA terms. Table 1 contains the estimation results. It can be observed that to capture the dynamics in stock return in $\mathrm{AR}$ specification an $\mathrm{AR}(2)$ and in MA specification an MA(2) model was estimated. The conditional mean models have not been augmented further with AR or MA terms as they were not significant (Figure A2, Appendix). Table 1 also contains the result for testing the existence of ARCH effect. It is revealed that in both $\mathrm{AR}(2)$ and $\mathrm{MA}(2)$ specification the test statistic for the null saying "there is no $A R C H$ effect" can be convincingly rejected with statistical evidence. Thus, the test is statistically significant implying that stock market return in Bangladesh is conditionally heteroscedastic. So, modeling the volatility clustering can be of important as it would help to analyze the inherent characteristics of the market in a more applied manner. The existence of volatility clustering in stock return series has also been found evident from the residual plot in Figure A3 (Appendix).

Since ARCH effect was present we have tried to model the volatility clustering using GARCH family models and explain the characteristics of the market while capturing its variance dynamics. To begin with we have estimated standard GARCH model both with $\mathrm{AR}(2)$ and $\mathrm{MA}(2)$ conditional mean specification. Table A3 (Appendix) and Table 2 contains the estimation results. As the results show in AR-GARCH specification the AR(1) coefficient is significant in all the models while the $\operatorname{AR}(2)$ coefficient was insignificant. Almost in all specifications

Table 1. Estimation of different conditional mean models and testing for ARCH effect.

\begin{tabular}{|c|c|c|}
\hline \multirow[t]{3}{*}{ Variables } & \multicolumn{2}{|c|}{ Coefficients } \\
\hline & \multicolumn{2}{|c|}{ Dependent Variable, $r_{t}$} \\
\hline & (AR) & (MA) \\
\hline \multirow[t]{2}{*}{$\mu$} & $0.0005^{\star *}$ & $0.0005^{\star *}$ \\
\hline & $(0.0002)$ & $(0.0002)$ \\
\hline \multirow[t]{2}{*}{$r_{t-1}$} & $0.0401^{* *}$ & \\
\hline & $(0.0184)$ & \\
\hline \multirow[t]{2}{*}{$\boldsymbol{r}_{t-2}$} & $-0.0430^{* *}$ & \\
\hline & $(0.0184)$ & \\
\hline \multirow[t]{2}{*}{$\varepsilon_{t-1}$} & & $0.0402^{\star *}$ \\
\hline & & $(0.0184)$ \\
\hline \multirow[t]{2}{*}{$\varepsilon_{t-2}$} & & $-0.0397^{\star *}$ \\
\hline & & $(0.0184)$ \\
\hline \multicolumn{3}{|c|}{$H_{O}:$ No ARCH Effect } \\
\hline F-Statistic & 134.9106 & 134.8517 \\
\hline Probability & 0.0000 & 0.0000 \\
\hline
\end{tabular}

Note: Standard Errors are in Parenthesis. ${ }^{* *}$ indicates significant at 10 per cent level, ${ }^{* *}$ significant at 5 per cent level and ${ }^{\star}$ indicates that at 1 per cent level. 
Table 2. Estimation results of GARCH models with MA mean specification.

\begin{tabular}{|c|c|c|c|c|c|}
\hline \multirow{2}{*}{ Coefficients } & \multicolumn{5}{|c|}{ GARCH } \\
\hline & $(1,1)$ & $(1,2)$ & $(1,3)$ & $(1,4)$ & $(2,1)$ \\
\hline \multirow[t]{2}{*}{$\mu$} & $0.0014^{* *}$ & $0.0034^{*}$ & $0.0033^{*}$ & $0.0013^{\star *}$ & $0.0013^{* *}$ \\
\hline & $(0.0006)$ & $(0.0003)$ & $(0.0003)$ & $(0.0006)$ & $(0.0005)$ \\
\hline \multirow[t]{2}{*}{$\phi_{1}$} & $0.0862^{\star * *}$ & $0.0629^{\star *}$ & $0.0657^{* * *}$ & $0.0987^{\star * *}$ & $0.1096^{* *}$ \\
\hline & $(0.0469)$ & $(0.0312)$ & $(0.0363)$ & $(0.0523)$ & $(0.0461)$ \\
\hline \multirow[t]{2}{*}{$\phi_{2}$} & -0.0384 & $-0.0435^{\star \star}$ & -0.0197 & -0.0322 & -0.0389 \\
\hline & $(0.0323)$ & $(0.0215)$ & $(0.0213)$ & $(0.0422)$ & $(0.0366)$ \\
\hline \multirow[t]{2}{*}{$\eta$} & $1.25 \mathrm{E}-05$ & $6.11 \mathrm{E}-05^{\star}$ & $3.49 \mathrm{E}-05^{\star}$ & $5.38 \mathrm{E}-06^{*}$ & $1.29 \mathrm{E}-05^{\star *}$ \\
\hline & $(7.73 \mathrm{E}-06)$ & $(2.58 \mathrm{E}-06)$ & $(2.88 \mathrm{E}-06)$ & $(1.86 \mathrm{E}-06)$ & $(5.91 \mathrm{E}-06)$ \\
\hline \multirow[t]{2}{*}{$\alpha_{1}$} & $0.3465^{*}$ & $0.3195^{\star}$ & $0.3365^{*}$ & $0.2770^{\star}$ & $0.1839^{\star *}$ \\
\hline & $(0.1104)$ & $(0.0490)$ & $(0.0332)$ & $(0.0911)$ & $(0.0850)$ \\
\hline \multirow[t]{2}{*}{$\alpha_{2}$} & & & & & 0.4115 \\
\hline & & & & & $(0.3785)$ \\
\hline \multirow[t]{2}{*}{$\boldsymbol{\beta}_{1}$} & $0.6684^{*}$ & $0.7351^{*}$ & $0.9718^{*}$ & $1.4214^{*}$ & $0.5159^{*}$ \\
\hline & $(0.0789)$ & $(0.1755)$ & $(0.1252)$ & $(0.0963)$ & $(0.1580)$ \\
\hline \multirow[t]{2}{*}{$\boldsymbol{\beta}_{2}$} & & $-0.2042^{\star * *}$ & $-0.4266^{\star}$ & $-1.1294^{\star}$ & \\
\hline & & $(0.1121)$ & $(0.0965)$ & $(0.1612)$ & \\
\hline \multirow[t]{2}{*}{$\boldsymbol{\beta}_{3}$} & & & $0.0768^{\star}$ & $0.5980^{\star}$ & \\
\hline & & & $(0.0199)$ & $(0.1286)$ & \\
\hline \multirow[t]{2}{*}{$\boldsymbol{\beta}_{4}$} & & & & $-0.1167^{\star \star}$ & \\
\hline & & & & $(0.0496)$ & \\
\hline Q1 (5) & $33.554^{\star}$ & $31.074^{*}$ & $32.508^{*}$ & $36.777^{\star}$ & $32.264^{*}$ \\
\hline Q1 (10) & $39.896^{*}$ & $37.997^{*}$ & $38.392^{*}$ & $44.698^{*}$ & $40.258^{*}$ \\
\hline Q2 (5) & 0.1161 & 0.1643 & 0.0911 & 0.1289 & 0.2274 \\
\hline Q2 (10) & 0.3068 & 1.1046 & 0.1850 & 0.4465 & 0.5983 \\
\hline Log Likelihood & 8700.438 & 8530.647 & 8600.336 & 8740.959 & 8746.996 \\
\hline F Stat. & 0.0512 & $6.42 \mathrm{E}-05$ & 0.0252 & 0.0528 & 0.0132 \\
\hline Prob. & 0.8208 & 0.9936 & 0.8739 & 0.8093 & 0.9084 \\
\hline
\end{tabular}

Note: Robust Standard Errors are in Parenthesis. ${ }^{* * *}$ indicates significant at 10 per cent level, ${ }^{* *}$ indicates significant at 5 per cent level and ${ }^{\star}$ indicates that at 1 per cent level.

the constant, $\eta$ and the ARCH coefficient, $\alpha$ is positive and significant. However, though the GARCH coefficients denoted by $\beta$ has been found to be significant in all specifications the sign for many of them was not conventional. Also as the results show in most of the cases the sum of ARCH and GARCH coefficients turn out to be greater than or close to unity implying that for those, variance won't remain well behaved. The one exception can be found in $\operatorname{GARCH}(2,1)$ where the first ARCH coefficient along with the GARCH coeffi- 
cient was found to be positive significant while the second $\mathrm{ARCH}$ coefficient was insignificant. The sum of ARCH and GARCH coefficients remained less than unity with a positive significant constant. Thus it satisfies all the restrictions and might be a potential model.

The residuals of the GARCH models are needed to be white noise. Thus, a diagnostic test in the form of Ljung-Box Q test has been performed under the null hypothesis, ( $H_{0}$ : No Serial Correlation in the Error Term). We calculate Q-Statistics for the standardized residuals (Q1) and for their squared values (Q2). It can be seen that all Q1-Statistics are significant at 1 per cent level while the Q2-Statistics were not. Therefore autocorrelation was found when we test based on level residuals and that was absent when test based on squared residuals. Nevertheless as F-statistic turn out to be insignificant for all models, it can be argued that none of them have ARCH effect. As the post estimation diagnostic results was found to be same for all but $\operatorname{AR}(2)-\operatorname{GARCH}(2,1)$ is the one which satisfies the restrictions, it can be treated as the appropriate one. Here the models were not augmented further as the coefficients were not found to be significant.

While the variance modeling was performed with MA mean specification the findings turn out to be almost same. However, $\operatorname{MA}(2)-\operatorname{GARCH}(2,1)$ specification has been observed to follow all the required restrictions with the similar post diagnostic properties as $\operatorname{AR}(2)-\operatorname{GARCH}(2,1)$. It is evident from the findings that among these two the former one have higher (8746.99) log likelihood than the later (8739.313), also the information criteria for the former one (SIC = $-5.9597)$ is found to be lower than the later ( $\mathrm{SIC}=-5.9585)$. Therefore, modeling volatility of stock return with MA mean specification has been revealed to be more appropriate than its AR counterpart.

For introducing nonlinearity in the variance equation and analyzing the asymmetric feature of volatility in the stock market return we have estimated APACRH model. As MA specification was found to provide more appropriate result, for mean equation $\mathrm{MA}(2)$ specification was used. Table A4 (Appendix) contains the estimation results. In particular we have estimated $\mathrm{MA}(2)$ $\operatorname{APARCH}(1,1)$ model. Further augmentation has not been done as the coefficients were not significant. As the results show the coefficients $\alpha$ and $\beta$ have found to be statistically significant with a positive sign. The power parameter $\delta$ is also positive and significant. Thus the model satisfies all the restrictions. The significance and sign of the coefficient, $\gamma$ determines the leverage effect. Here, as the coefficient was not found to be significant, $\operatorname{MA}(2)-\operatorname{APARCH}(1,1)$ specification reveals that there is no leverage effect in stock market return in Bangladesh. Therefore, possibly there is no asymmetric volatility effect in the stock market return. The post estimation diagnostic results of this model show that there is no ARCH effect and there is no autocorrelation in the squared residuals.

As APARCH model failed to capture the asymmetric volatility effect which could potentially be present in the stock market, we have given effort to examine this feature using another volatility modeling approach called EGARCH. Unlike the earlier one it doesn't need to impose any non negativity restrictions while 
capturing the asymmetric volatility effect. Also, along with "asymmetry parameter" it estimates another parameter called "size parameter" measuring the size of shocks. Thus in contrast to APARCH, EGARCH can measure the existence of leverage effect as well as the magnitude of shock. Table 3 contains the estimation results. In particular we have estimated $\operatorname{EGARCH}(1,1), \operatorname{EGARCH}(1,2)$ and $\operatorname{EGARCH}(1,3)$ for variance equation while modeling the conditional mean with MA(2) specification. As the coefficients have not been found to be significant we didn't augment the model further. Here $\beta$ s are the persistence parameters, $\alpha$ is the parameter and $\gamma$ is the size parameter. It can be observed that in all specifications the persistence parameters and the asymmetry parameters are statistically significant. In particular, the asymmetry parameter was statistically significant with a positive sign. Thus there exists significant leverage effect and the effect of "good news" and "bad news" in the stock market return does not necessarily cause symmetric variation in the stock return. As the leverage coefficient is found to have a positive sign, it can be argued that positive shocks (good news) increases volatility more than the negative shocks (bad news) of the same magnitude.

The results on diagnostic indicators shows that $\operatorname{MA}(2)-\operatorname{EGARCH}(1,2)$ specification have autocorrelation problem as well as the model still contains ARCH effect (as F-Statistic is significant). Nonetheless, $\operatorname{MA}(2)-\operatorname{EGARCH}(1,1)$ and $\operatorname{MA}(2)$ - EGARCH $(1,3)$ have no autocorrelation when we considers the squared residuals. Also, they do not have any $\mathrm{ARCH}$ effect reveled by insignificant F-Statistic. So, these two specifications are better than the earlier one. Among them log likelihood is maximum (8815.42) and information criteria is minimum (SIC $=-6.0010)$ for $\mathrm{MA}(2)-\operatorname{EGARCH}(1,3)$. Thus, it could be the potentially appropriate model for capturing the asymmetric effect in stock market return.

Finally we have given effort to model the volatility clustering in stock return addressing the restriction saying that "persistence parameters sum up to unit". The rationale for this restriction is that earlier in some of the GARCH models it was found that the sum of the coefficients were close to or more than unit implying that the variance of stock return might be nonstationary. Imposing this restriction in standard GARCH models leads to IGARCH specification. Table A5 (Appendix) contains the estimation results of different IGARCH specification with $\mathrm{MA}(2)$ conditional mean model. As the results show $\operatorname{IGARCH}(1,1)$ and also $\operatorname{IGARCH}(1,3)$ have autocorrelation and $\mathrm{ARCH}$ effect. But the $\operatorname{IGARCH}(1,2)$ have no autocorrelation in the squared residuals and also there is no ARCH effect. It also satisfies the imposed restriction and the significance of persistence parameter indicates that there is volatility clustering in stock market return. It also contains maximum likelihood (8582.32) and minimum information criteria (SIC $=-5.8526)$ compared to the other two.

\subsection{Out of Sample Forecasting Accuracy}

With a view to choose among the models we have compared the performance among them in terms of accuracy of out of sample volatility forecasting. The 
Table 3. Estimation results for EGARCH model with MA specification.

\begin{tabular}{|c|c|c|c|}
\hline \multirow{2}{*}{ Variables } & \multicolumn{3}{|c|}{ EGARCH with Normal Distribution } \\
\hline & $(1,1)$ & $(1,2)$ & $(1,3)$ \\
\hline \multirow[t]{2}{*}{$\mu$} & 0.0001 & 0.0001 & $0.0005^{\star *}$ \\
\hline & $(0.0002)$ & $(0.0003)$ & $(0.0002)$ \\
\hline \multirow[t]{2}{*}{$\phi_{1}$} & $0.1489^{*}$ & $0.1411^{\star}$ & $0.1542^{*}$ \\
\hline & $(0.0220)$ & $(0.0226)$ & $(0.0222)$ \\
\hline \multirow[t]{2}{*}{$\phi_{2}$} & 0.0135 & $0.0482^{* * *}$ & 0.0325 \\
\hline & $(0.0556)$ & $(0.0260)$ & $(0.0580)$ \\
\hline \multirow[t]{2}{*}{$\eta$} & $-1.2659^{*}$ & $-0.2956^{*}$ & $-0.5718^{\star}$ \\
\hline & $(0.4370)$ & $(0.0737)$ & $(0.1038)$ \\
\hline \multirow[t]{2}{*}{$\alpha$} & $0.4865^{*}$ & $0.1611^{\star}$ & $0.3038^{\star}$ \\
\hline & $(0.1149)$ & $(0.0201)$ & $(0.0432)$ \\
\hline \multirow[t]{2}{*}{$\lambda$} & $-0.1527^{* * *}$ & 0.0147 & $-0.0988^{* *}$ \\
\hline & $(0.0914)$ & $(0.0090)$ & $(0.0526)$ \\
\hline \multirow[t]{2}{*}{$\boldsymbol{\beta}_{1}$} & $0.8945^{\star}$ & $0.0200^{*}$ & $1.7725^{\star}$ \\
\hline & $(0.0450)$ & $(0.0042)$ & $(0.0846)$ \\
\hline \multirow[t]{2}{*}{$\boldsymbol{\beta}_{2}$} & & $0.9594^{\star}$ & $-1.4774^{*}$ \\
\hline & & $(0.0045)$ & $(0.1270)$ \\
\hline \multirow[t]{2}{*}{$\boldsymbol{\beta}_{3}$} & & & $0.6649^{\star}$ \\
\hline & & & $(0.0408)$ \\
\hline Q1 (5) & $21.938^{*}$ & $21.402^{\star}$ & $27.451^{\star}$ \\
\hline Q1 (10) & $28.350^{*}$ & $29.040^{*}$ & $33.939^{*}$ \\
\hline Q2 (5) & 0.0892 & $25.218^{\star}$ & 0.2585 \\
\hline Q2 (10) & 0.2739 & $27.467^{\star}$ & 1.0130 \\
\hline Log Likelihood & 8744.181 & 8715.984 & 8815.427 \\
\hline F Statistic & 0.0467 & $13.547^{\star}$ & 0.0102 \\
\hline Probability & 0.8288 & 0.000 & 0.9193 \\
\hline
\end{tabular}

Note: Robust Standard Errors are in Parenthesis. ${ }^{* *}$ indicates significant at 10 per cent level, ${ }^{* *}$ indicates significant at 5 per cent level and ${ }^{*}$ indicates that at 1 per cent level.

pseudo sample has been created using the observations for the period $27^{\text {th }}$ November, 2001 to $30^{\text {th }}$ December 2010. The forecasting accuracy of different models was compared in terms of RMSE, MAE, MAPE and TI for the period $2^{\text {nd }}$ January 2011 to $31^{\text {st }}$ July, 2013. Table 4 contains the results. As it can be observed when forecasting is performed with different specification of standard GARCH-MA(2) mean model RMSE and MAE is equal for all the models. But, MAPE is lowest with the value 180.713 for $\operatorname{MA}(2)-\operatorname{GARCH}(2,1)$ and also TI is lowest with the value 0.875 (only exception is $\operatorname{MA}(2)-\operatorname{GARCH}(1,4)$ where TI is 0.872). Earlier when full sample was used it was found that this specification 
Table 4. Out of sample forecasting accuracy of different models.

\begin{tabular}{|c|c|c|c|c|c|}
\hline \multicolumn{6}{|c|}{ MA(2) - GARCH } \\
\hline & $(1,1)$ & $(1,2)$ & $(1,3)$ & $(1,4)$ & $(2,1)$ \\
\hline RMSE & 0.023 & 0.023 & 0.023 & 0.023 & 0.023 \\
\hline MAE & 0.016 & 0.016 & 0.016 & 0.016 & 0.016 \\
\hline MAPE & 196.103 & 199.519 & 201.053 & 201.076 & 180.713 \\
\hline \multirow[t]{3}{*}{ TI } & 0.880 & 0.876 & 0.879 & 0.872 & 0.875 \\
\hline & & \multicolumn{2}{|c|}{ MA(2) - EGARCH } & \multicolumn{2}{|c|}{ MA(2) - APARCH } \\
\hline & & $(1,1)$ & $(1,3)$ & & 1) \\
\hline RMSE & & 0.024 & 0.024 & & \\
\hline MAE & & 0.016 & 0.016 & & \\
\hline MAPE & & 185.595 & 203.204 & & \\
\hline TI & & 0.858 & 0.850 & & 0.781 \\
\hline
\end{tabular}

satisfies all the required restrictions and revealed the volatility clustering feature of stock return appropriately. Thus if the purpose is only modeling the volatility clustering and forecasting the future volatility then $\operatorname{MA}(2)-\operatorname{GARCH}(2,1)$ will perform better.

When we have tried to forecast the volatility in stock return while addressing the asymmetric affect it was found again that in terms of RMSE and MAE, $\operatorname{MA}(2)-\operatorname{EGARCH}(1,1), \operatorname{MA}(2)-\operatorname{EGARCH}(1,3)$ and $\operatorname{MA}(2)-\operatorname{APARCH}(1,1)$ all are same. In terms of TI, MA(2) - $\operatorname{EGARCH}(1,3)$ is better than $\operatorname{MA}(2)-$ $\operatorname{EGARCH}(1,1)$ while its other way around in terms of MAPE. However, among EGARCH and APARCH, MA(2) - APARCH $(1,1)$ has the lowest value both for TI and MAPE. Nevertheless, earlier it was observed that APARCH model failed to capture the asymmetric volatility effect. Thus, if the purpose is to capture the asymmetric volatility effect along with forecasting then the appropriate model would be $\mathrm{MA}(2)$ - $\operatorname{EGARCH}(1,3)$ as it was able to capture the asymmetric volatility effect appropriately. It also had maximum likelihood and minimum information criteria when full sample was used and have a lower TI value when out of sample forecasting is considered. Figure A4 (Appendix) contains the forecasted volatility along with the confidence interval for the aforementioned models.

\section{Conclusions and Policy Relevance}

An efficient and well behaved capital market can be regarded as a prerequisite for the sustainable financial development for an economy. The importance appeared to be even more crucial when the country is in early stage of development as characteristics and behavior of this market is and usually does maintain a close relation to the other macroeconomic indicators. Therefore modeling and forecasting the variance dynamics of stock market return in Bangladesh has gained a greater attention from the academicians and researchers, since the country has been trying to develop an efficient capital market from a long ago. 
Modeling of conditional variance of stock return also has greater relevance for taking decision by the investors and policy makers regarding portfolio optimization, asset pricing and finally risk management. An appropriate variance model will help concerned people to have a better forecast of volatility which in turn would be significant for having efficient portfolio distribution, better risk management capacity and more specific derivative prices for particular financial instrument.

Identifying appropriate volatility model for capturing fluctuations in stock returns is of significant policy relevance to the policy makers as well. The importance lies on the fact that unregulated fluctuation in asset return could influence investment decision that can manifest in the real sector with adverse consequences for economic growth and development. Undue fluctuation of stock return could also impose challenges to monetary policy formulation as increase in stock prices stimulates interest rate which eventually could generate inflationary spree in the economy [23] [24]. In this regard, stabilization policy is required and the specification of optimal volatility model for capturing variations in stock returns makes a pre-condition for the monetary authority intervention.

In the above context this paper goes with challenge of exploring comparative ability of capturing in-sample and out-of-sample volatility of different conditionally heteroscedastic econometric models regarding stock market return in Bangladesh. More specifically, it explored daily data for the period $27^{\text {th }}$ November, 2001 to $31^{\text {st }}$ July, 2013 from DSE and has used different GARCH class models to compare their performance form in-sample estimation accuracy and out-of-sample forecasting accuracy perspective to come up with the best performing one. By developing appropriate mean equation for addressing the autocorrelation problem the paper compared different order of variance models namely, GARCH, APARCH, EGARCH and IGRACH. While concerning in sample estimation accuracy it was found that $\operatorname{MA}(2)-\operatorname{GARCH}(2,1)$ out performs $\operatorname{AR}(2)-\operatorname{GARCH}(2,1)$ following post estimation diagnostics. When nonlinearity was allowed in variance equation to capture the asymmetric effect $\operatorname{MA}(2)-\operatorname{EGARCH}(1,3)$ was found to be successful over MA(2) - $\operatorname{APARCH}(1$, $1)$. By assuming that variance could potentially be remained nonstationary it was observed that $\operatorname{MA}(2)-\operatorname{IGARCH}(1,2)$ has more in sample accuracy than its other counterparts. As far as out of sample volatility forecasting is concerned it was found that for only modeling the volatility clustering $\operatorname{MA}(2)-\operatorname{GARCH}(2,1)$ out performs the other. However, for modeling the volatility clustering addressing the asymmetric effect MA(2) - $\operatorname{EGARCH}(1,3)$ provides more out of sample accurate result among its competing ones. Therefore, it can be argued with evidence that there is no clear winner. The decision mainly depends on the purpose of the concerned people. From volatility persistency perspective MA(2) $\operatorname{GARCH}(2,1)$ is better due to both in sample and out of sample accuracy. In contrast, from capturing asymmetric effect perspective $\mathrm{MA}(2)-\operatorname{EGARCH}(1,3)$ is better.

One potential shortcoming of the current effort could be that it did not in- 
corporate the issue of existence of structural break in the variance dynamics while modeling the conditional heteroscedasticity. Nevertheless, addressing the structural break in variance dynamics could remain as a further area of research.

\section{Conflicts of Interest}

The authors declare no conflicts of interest regarding the publication of this paper.

\section{References}

[1] Rajni, M. and Mahendra, R. (2007) Measuring Stock Market Volatility in an Emerging Economy. International Research Journal of Finance \& Economics, 8, 126-133.

[2] Zuliu, H. (1995) Stock Market Volatility and Corporate Investment. IMF Working Paper, 95-102.

[3] Levine, R. and Zervous, S. (1996) Stock Market Development and Long-Run Growth. World Bank Economic Review, 10, 323-339. https://doi.org/10.1093/wber/10.2.323

[4] Olowe, R.A. (2009) Stock Return, Volatility \& the Global Financial Crisis in an Emerging Market: The Nigerian Case. International Review of Business Research Papers, 5, 426-447.

[5] Olowe, R.A. (2009) The Impact of the Announcement of the 2005 Capital Requirement for Insurance Companies on the Nigerian Stock Market. The Nigerian Journal of Risk and Insurance, 6, 43-69.

[6] Chowdhury, A.R. (1994) Statistical Properties of Daily Returns from the Dhaka Stock Exchange. The Bangladesh Development Studies, 22, 61-76.

[7] Basher, S.A., Hassan, M.K. and Islam, A.M. (2007) Time-Varying Volatility and Equity Returns in Bangladesh Stock Market. Applied Financial Economics, 17, 1393-1407. https://doi.org/10.1080/09603100600771034

[8] Rayhan, M.A., Sarker, S.A. and Sayem, S.M. (2011) The Volatility of Dhaka Stock Exchange (DSE) Returns: Evidence and Implications. ASA University Review, 5, 97-99.

[9] Rahman, M.M., Huq, M.M. and Rahman, M.S. (2012) In Sample and Out of Sample Forecasting Performance under Fat Tail and Skewed Distribution. Proceeding Book of International Conference on Statistical Data Mining for Bioinformatics, Health, Agricultural and Environment, Department of Statistics, University of Rajshahi, December 2012, 462-472.

[10] Islam, M., Ali, L.E. and Afroz, N. (2012) Forecasting Volatility of Dhaka Stock Exchange: Linear Vs Non-Linear Models. International Journal of Science and Engineering, 3, 4-8.

[11] Huq, M.M., Rahman, M.M., Rahman, M.S., Shahin, M.M. and Ali, M. (2013) Analysis of Volatility and Forecasting General Index of Dhaka Stock Exchange. American Journal of Economics, 3, 229-242.

[12] Alam, M.Z., Siddikee, M.N. and Masukujjaman, M. (2013) Forecasting Volatility of Stock Indices with ARCH Model. International Journal of Financial Research, 4, 126-143. https://doi.org/10.5430/ijfr.v4n2p126

[13] Aziz, M.S. and Uddin, M.N. (2014) Volatility Estimation in the Dhaka Stock Exchange (DSE) Returns by Garch Models. Asian Business Review, 4, 41-49. 
https://doi.org/10.18034/abr.v4i1.72

[14] Miah, M. and Rahman, A. (2016) Modelling Volatility of Daily Stock Returns: Is GARCH(1,1) Enough? American Scientific Research Journal for Engineering, Technology, and Sciences (ASRJETS), 18, 29-39.

[15] Uddin, M., Islam, M.S. and Majumder, M.A. (2016) Market Efficiency, Time-Varying Volatility and Equity Returns in the Dhaka Stock Exchange. World Review of Business Research, 6, 43-62.

[16] Bollerslev, T. (1986) Generalised Autoregressive Conditional Heteroskedasticity. Journal of Econometrics, 31, 307-327. https://doi.org/10.1016/0304-4076(86)90063-1

[17] Erdemlioglu, D., Laurent, S. and Neely, C.J. (2012) Econometric Modeling of Exchange Rate Volatility and Jumps. Working Paper, Federal Reserve Bank of St. Louis.

[18] Engle, R.F. (1982) Autoregressive Conditional Heteroskedasticity with Estimates of the Variance of United Kingdom Inflation. Econometrica, 50, 987-1007. https://doi.org/10.2307/1912773

[19] Ding, Z., Granger, C.W. and Engle, R.F. (1993) A Long Memory Property of Stock Market Returns and a New Mode. Journal of Empirical Finance, 1, 83-106. https://doi.org/10.1016/0927-5398(93)90006-D

[20] Nelson, D. (1991) Conditional Heteroskedasticity in Asset Returns: A New Approach. Econometrica, 59, 347-370. https://doi.org/10.2307/2938260

[21] Dickey, D.A. and Fulle, W.A. (1979) Distribution of the Estimators for Autoregressive Time Series with a Unit Root. Journal of the American Statistical Association, 74, 427-431. https://doi.org/10.1080/01621459.1979.10482531

[22] Kwiatkowski, D., Phillips, P.C., Schmidt, P. and Shin, Y. (1992) Testing the Null Hypothesis of Stationarity against the Alternative of a Unit Root: How Sure Are We That Economic Time Series Have a Unit Root? Journal of Econometrics, 54, 159-178. https://doi.org/10.1016/0304-4076(92)90104-Y

[23] Fischer, S. (1981) Relative Stocks, Relative Price Variability, and Inflation. Brookings Paper on Economic Activity, 1981, 381-441. https://doi.org/10.2307/2534344

[24] Veronesi, P. (1999) Market Overreactions to Bad News in Good Times: A Rational Expectations Equilibrium Model. The Review of Financial Studies, 12, 975-1007. https://doi.org/10.1093/rfs/12.5.975 


\section{Appendix}

Table A1. Summary statistics of DSE index.

\begin{tabular}{cccccc}
\hline Variable & Mean & Median & Std. Deviation & Skewness & Kurtosis \\
\hline DSE General Index & 2810.734 & 2074.550 & 1935.526 & 0.897 & 2.847 \\
\hline
\end{tabular}

Table A2. Staionarity test results for the stock return series.

\begin{tabular}{|c|c|c|c|c|c|c|c|}
\hline \multicolumn{4}{|c|}{ Augmented Dickey Fuller (ADF) Test } & \multicolumn{4}{|c|}{ Kwiatkowski-Philips-Schmidt-Shin (KPSS) Test } \\
\hline \multicolumn{4}{|c|}{$H_{0}:$ Stock Return has a Unit Root } & \multicolumn{4}{|c|}{$H_{0}:$ Stock Return is Stationary } \\
\hline \multicolumn{2}{|c|}{ Intercept } & \multicolumn{2}{|c|}{ Trend and Intercept } & \multicolumn{2}{|c|}{ Intercept } & \multicolumn{2}{|c|}{ Trend and Intercept } \\
\hline Test Statistic & Probability & Test Statistic & Probability & Test Statistic & $1 \%$ Critical Value & Test Statistic & $1 \%$ Critical Value \\
\hline$-52.0260^{*}$ & 0.0000 & -52.0246 & 0.0000 & 0.174 & 0.739 & 0.133 & 0.216 \\
\hline \multicolumn{2}{|c|}{ Optimum Order of Lag is Zero } & \multicolumn{2}{|c|}{ Optimum Order of Lag is Zero } & \multicolumn{2}{|c|}{ Optimum Bandwidth is Nine } & \multicolumn{2}{|c|}{ Optimum Bandwidth is Eight } \\
\hline
\end{tabular}

Note: ${ }^{*}$ indicates significant at $1 \%$ level. In case of selecting optimal lag length for ADF test, the SIC has been minimized. The optimum bandwidth for KPSS test has been selected using Newey-West method and following Bartlett Kernel for spectral estimation.

Table A3. Estimation results of GARCH models with AR mean specification.

\begin{tabular}{|c|c|c|c|c|c|c|}
\hline \multirow{2}{*}{ Coefficients } & \multicolumn{6}{|c|}{ GARCH } \\
\hline & $(1,1)$ & $(1,2)$ & $(1,3)$ & $(1,4)$ & $(1,5)$ & $(2,1)$ \\
\hline \multirow[t]{2}{*}{$\mu$} & $0.0014^{\star *}$ & $0.0014^{\star \star}$ & $0.0031^{\star}$ & $0.0013^{* *}$ & $0.0012^{* * *}$ & $0.0012^{\star \star}$ \\
\hline & $(0.0006)$ & $(0.0006)$ & $(0.0003)$ & $(0.0006)$ & $(0.0006)$ & $(0.0005)$ \\
\hline \multirow[t]{2}{*}{$\theta_{1}$} & $0.0812^{\star * *}$ & $0.0936^{* * *}$ & 0.0313 & $0.0950^{* * *}$ & $0.1005^{\star *}$ & $0.1039^{* *}$ \\
\hline & $(0.0483)$ & $(0.0507)$ & $(0.0388)$ & $(0.0531)$ & $(0.0512)$ & $(0.0477)$ \\
\hline \multirow[t]{2}{*}{$\theta_{2}$} & -0.0310 & -0.0391 & -0.0319 & -0.0290 & -0.0352 & -0.0360 \\
\hline & $(0.0402)$ & $(0.0460)$ & $(0.0236)$ & $(0.0548)$ & $(0.0543)$ & $(0.0492)$ \\
\hline \multirow[t]{2}{*}{$\eta$} & $1.25 \mathrm{E}-05$ & $9.83 \mathrm{E}-06^{*}$ & $3.53 \mathrm{E}-05^{\star}$ & $5.29 \mathrm{E}-06^{*}$ & $3.50 \mathrm{E}-06^{*}$ & $1.27 \mathrm{E}-05^{\star *}$ \\
\hline & $(7.68 \mathrm{E}-06)$ & $(3.08 \mathrm{E}-06)$ & $(2.84 \mathrm{E}-06)$ & $(1.79 \mathrm{E}-06)$ & $(6.07 \mathrm{E}-07)$ & $(5.87 \mathrm{E}-06)$ \\
\hline \multirow[t]{2}{*}{$\alpha_{1}$} & $0.3458^{*}$ & $0.3187^{\star}$ & $0.3498^{\star}$ & $0.2738^{*}$ & $0.2282^{* *}$ & $0.1829^{\star *}$ \\
\hline & $(0.1111)$ & $(0.0703)$ & $(0.0341)$ & $(0.0878)$ & $(0.0911)$ & $(0.0841)$ \\
\hline \multirow[t]{2}{*}{$\alpha_{2}$} & & & & & & 0.4092 \\
\hline & & & & & & $(0.3770)$ \\
\hline \multirow[t]{2}{*}{$\beta_{1}$} & $0.6695^{*}$ & $0.9743^{*}$ & $0.9816^{*}$ & $1.4296^{\star}$ & $1.7836^{*}$ & $0.5187^{*}$ \\
\hline & $(0.0791)$ & $(0.0821)$ & $(0.1204)$ & $(0.1068)$ & $(0.0961)$ & $(0.1580)$ \\
\hline \multirow[t]{2}{*}{$\boldsymbol{\beta}_{2}$} & & $-0.2596^{*}$ & $-0.4264^{*}$ & $-1.1306^{*}$ & $-1.9036^{*}$ & \\
\hline & & $(0.0812)$ & $(0.0910)$ & $(0.1831)$ & $(0.1880)$ & \\
\hline \multirow[t]{2}{*}{$\boldsymbol{\beta}_{3}$} & & & $0.0732^{*}$ & $0.5869^{*}$ & $1.5081^{*}$ & \\
\hline & & & $(0.0160)$ & $(0.1394)$ & $(0.2141)$ & \\
\hline \multirow[t]{2}{*}{$\beta_{4}$} & & & & $-0.1099^{* *}$ & $-0.8152^{\star}$ & \\
\hline & & & & $(0.0548)$ & $(0.1469)$ & \\
\hline \multirow[t]{2}{*}{$\boldsymbol{\beta}_{5}$} & & & & & $0.2462^{\star}$ & \\
\hline & & & & & $(0.0517)$ & \\
\hline Q1 (5) & $35.381^{*}$ & $34.211^{*}$ & $48.953^{*}$ & $37.973^{*}$ & $35.341^{\star}$ & $34.203^{*}$ \\
\hline Q1 (10) & $41.864^{*}$ & $41.195^{*}$ & $56.104^{*}$ & $45.295^{*}$ & $45.573^{\star}$ & $42.249^{\star}$ \\
\hline Q2 (5) & 0.1167 & 0.1709 & 0.1029 & 0.1291 & 0.141 & 0.227 \\
\hline Q2 (10) & 0.3078 & 0.3840 & 0.3891 & 0.449 & 0.423 & 0.601 \\
\hline Log Likelihood & 8693.102 & 8710.725 & 8584.991 & 8733.666 & 8743.978 & 8739.313 \\
\hline F Stat. & 0.0518 & 0.0564 & 0.024 & 0.058 & 0.040 & 0.013 \\
\hline Prob. & 0.8199 & 0.8122 & 0.874 & 0.809 & 0.841 & 0.906 \\
\hline
\end{tabular}

Note: Robust Standard Errors are in Parenthesis. ${ }^{* *}$ indicates significant at 10 per cent level, ${ }^{* *}$ indicates significant at 5 per cent level and ${ }^{*}$ indicates that at 1 per cent level. 
Table A4. APARCH with MA mean specification.

\begin{tabular}{|c|c|}
\hline Coefficients & $\operatorname{APARCH}(1,1)$ \\
\hline \multirow[t]{2}{*}{$\mu$} & $0.0004^{* *}$ \\
\hline & $(0.0002)$ \\
\hline \multirow[t]{2}{*}{$\phi_{1}$} & $0.1231^{\star}$ \\
\hline & $(0.0224)$ \\
\hline \multirow[t]{2}{*}{$\phi_{2}$} & -0.0088 \\
\hline & $(0.0460)$ \\
\hline \multirow[t]{2}{*}{$\eta$} & 0.0002 \\
\hline & $(0.0001)$ \\
\hline \multirow[t]{2}{*}{$\alpha$} & $0.2867^{*}$ \\
\hline & $(0.0763)$ \\
\hline \multirow[t]{2}{*}{$\gamma$} & 0.2901 \\
\hline & $(0.1907)$ \\
\hline \multirow[t]{2}{*}{$\delta$} & $1.3731^{*}$ \\
\hline & $(0.2603)$ \\
\hline \multirow[t]{2}{*}{$\beta$} & $0.7070^{*}$ \\
\hline & $(0.0812)$ \\
\hline Q1 (5) & $26.810^{*}$ \\
\hline Q1 (10) & $33.524^{*}$ \\
\hline Q2 (5) & 0.0719 \\
\hline Q2 (10) & 0.2538 \\
\hline Log Likelihood & 8740.570 \\
\hline F Stat. & 0.0357 \\
\hline Prob. & 0.8501 \\
\hline
\end{tabular}

Note: Robust Standard Errors are in Parenthesis. ${ }^{* *}$ indicates significant at 10 per cent level, ${ }^{* *}$ indicates significant at 5 per cent level and ${ }^{*}$ indicates that at 1 per cent level. 
Table A5. Estimation results for IGARCH model with MA mean specification.

\begin{tabular}{|c|c|c|c|}
\hline \multirow{2}{*}{ Variables } & \multicolumn{3}{|c|}{ IGARCH with Normal Distribution } \\
\hline & $(1,1)$ & $(1,2)$ & $(1,3)$ \\
\hline \multirow[t]{2}{*}{$\mu$} & 0.0003 & 0.0001 & 0.0003 \\
\hline & $(0.0002)$ & $(0.0002)$ & $(0.0002)$ \\
\hline \multirow[t]{2}{*}{$\phi_{1}$} & $0.0908^{*}$ & $0.1123^{*}$ & $0.0879^{\star}$ \\
\hline & $(0.0335)$ & $(0.0305)$ & $(0.0326)$ \\
\hline \multirow[t]{2}{*}{$\phi_{2}$} & -0.0390 & -0.0465 & -0.0468 \\
\hline & $(0.0280)$ & $(0.0298)$ & $(0.0287)$ \\
\hline \multirow[t]{2}{*}{$\alpha$} & 0.0109 & 0.0292 & $0.0140^{* *}$ \\
\hline & $(0.0089)$ & $(0.0188)$ & $(0.0069)$ \\
\hline \multirow[t]{2}{*}{$\boldsymbol{\beta}_{1}$} & $0.9890^{*}$ & -0.0015 & $1.4322^{*}$ \\
\hline & $(0.0089)$ & $(0.0040)$ & $(0.0109)$ \\
\hline \multirow[t]{2}{*}{$\boldsymbol{\beta}_{2}$} & & $0.9722^{*}$ & $-1.4204^{\star}$ \\
\hline & & $(0.0225)$ & $(0.0233)$ \\
\hline \multirow[t]{2}{*}{$\beta_{3}$} & & & $0.9741^{*}$ \\
\hline & & & $(0.0194)$ \\
\hline Q1 (5) & $16.274^{*}$ & $15.658^{*}$ & $20.861^{*}$ \\
\hline Q1 (10) & $25.969^{*}$ & $25.727^{\star}$ & $32.325^{*}$ \\
\hline Q2 (5) & 4.963 & 3.336 & $9.628^{* *}$ \\
\hline Q2 (10) & 5.545 & 3.890 & 11.767 \\
\hline Log Likelihood & 8529.451 & 8582.327 & 8573.475 \\
\hline F Statistic & $2.820^{* * *}$ & 1.578 & $4.475^{* *}$ \\
\hline Probability & 0.093 & 0.209 & 0.034 \\
\hline
\end{tabular}

Note: Robust Standard Errors are in Parenthesis. ${ }^{* *}$ indicates significant at 10 per cent level, ${ }^{* *}$ indicates significant at 5 per cent level and ${ }^{\star}$ indicates that at 1 per cent level. 


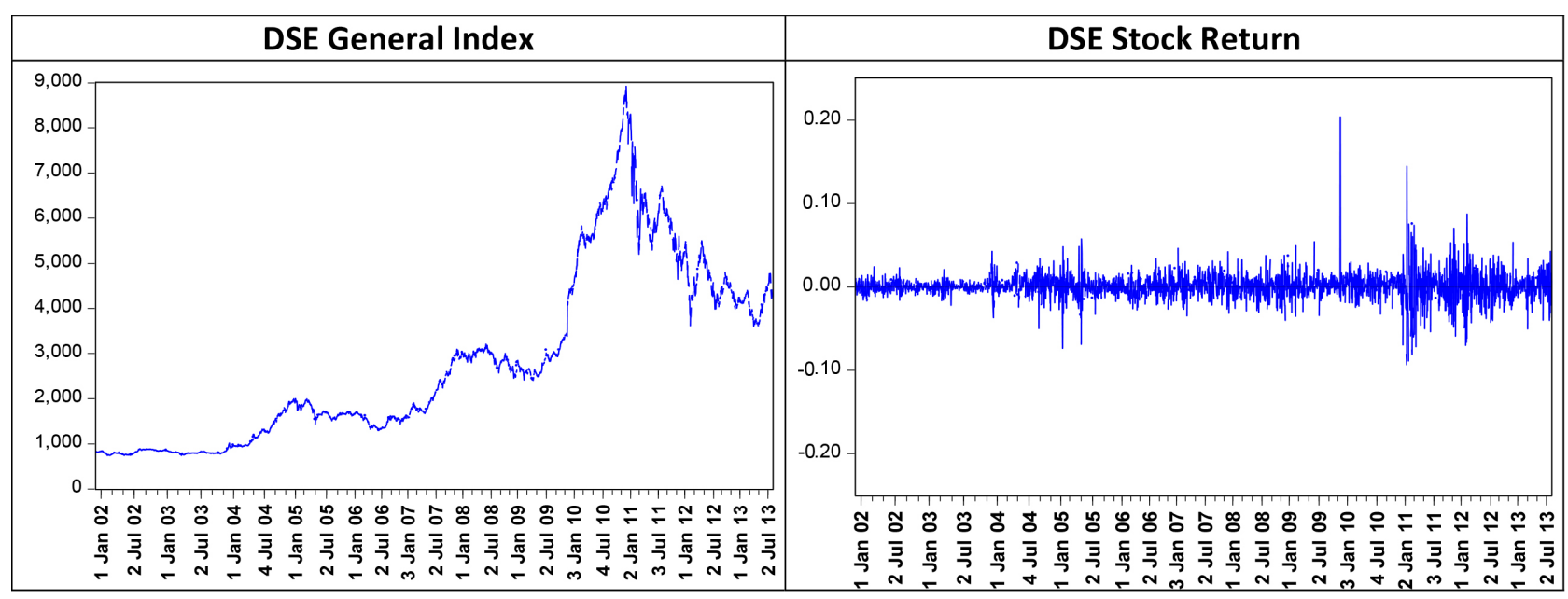

Figure A1. Time series graph of DSE general index and DSE stock return.

\begin{tabular}{c|c}
\hline \hline Autocorrelation & Partial Correlation \\
\hline \hline & \\
\hline
\end{tabular}

Figure A2. Correlogram of the stock return.

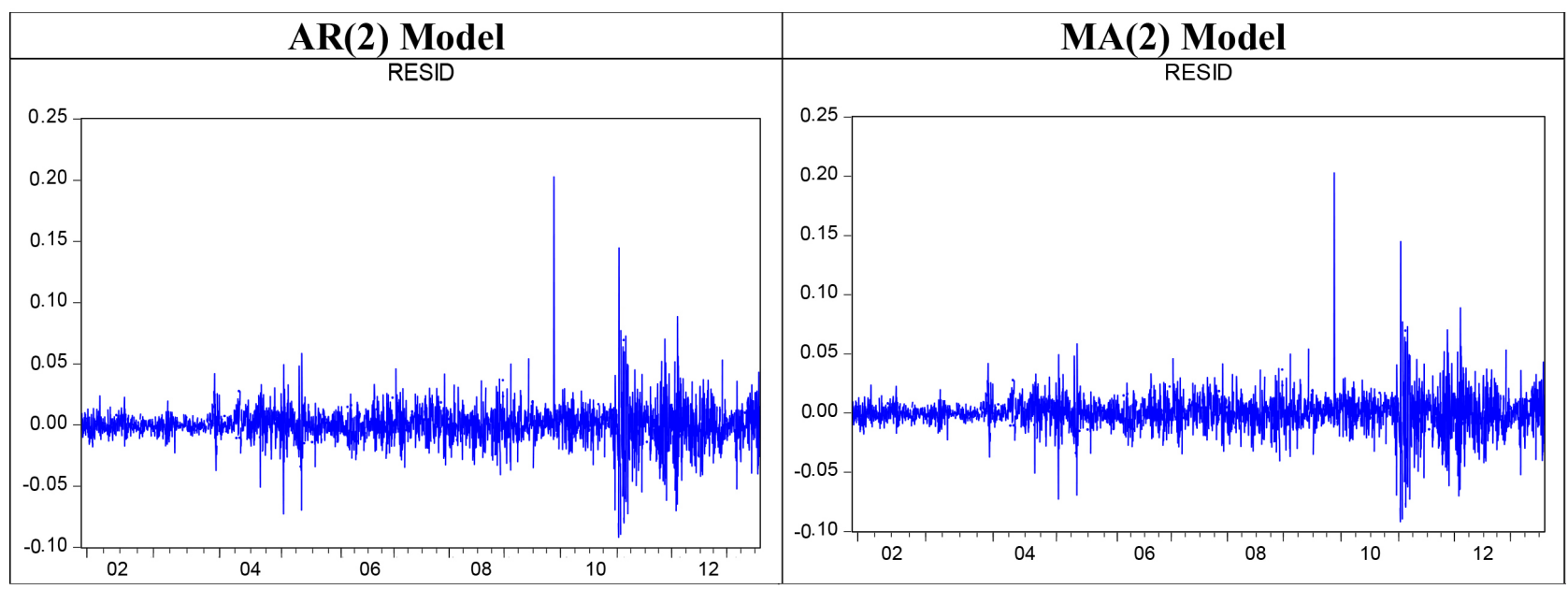

Figure A3. Volatility clustering of stock market return. 


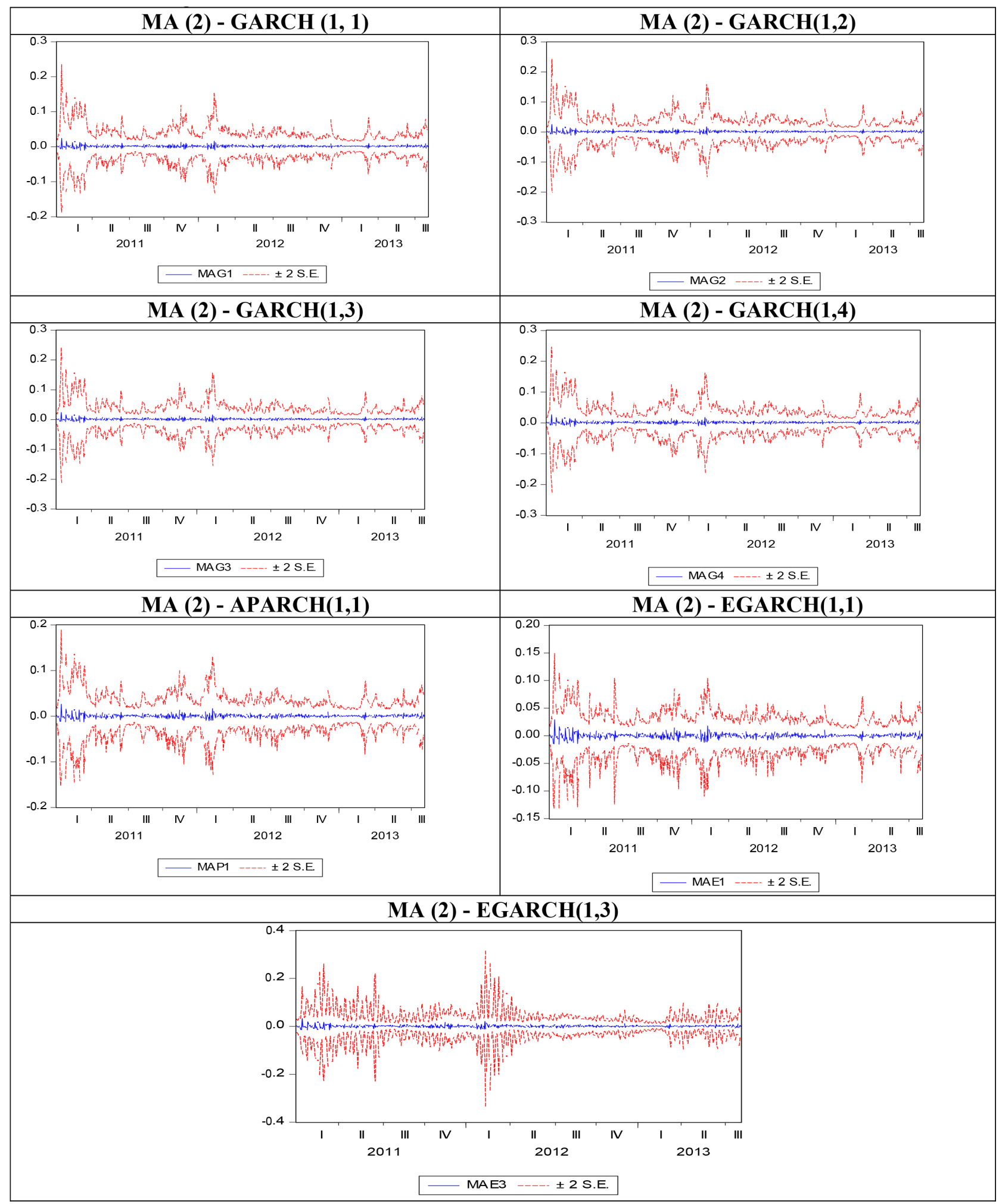

Figure A4. Out of sample forecasted volatility using different models. 